\title{
Multiobjective Optimization of Two-Stage Rockets for Earth-To-Orbit Launch
}

\author{
Brian K. Bairstow* \\ Massachusetts Institute of Technology, Cambridge, Massachusetts, 02139 \\ Olivier de Weck $^{\dagger}$ \\ Massachusetts Institute of Technology, Cambridge, Massachusetts, 02139 \\ and \\ Jaroslaw Sobieszczanski-Sobieski ${ }^{\ddagger}$ \\ NASA Langley Research Center, Hampton, Virginia, 23681-2199
}

\begin{abstract}
Rockets are defined by many variables and constraints, and ultimately deliver a payload to orbit at some cost. These characteristics provide the basis for an optimization problem. This paper describes the construction and optimization of a two-stage liquid rocket model. At the core of the model, the shooting method was used to calculate the fuel usage and ending altitude of the rocket design. The design space was examined using a multi-objective genetic algorithm. A wide range of feasible non-dominated rocket designs were found and these are presented in the paper. Sensitivity to various input parameters was also explored. The model will serve as a benchmark problem for future research and comparative analysis of a number of optimization algorithms.
\end{abstract}

\section{Nomenclature}

$\begin{array}{ll}A & =\text { altitude } \\ A_{\text {target }} & =\text { target orbit altitude } \\ A_{\text {final }} & =\text { ending altitude } \\ A_{\text {stage }} & =\text { staging altitude } \\ C & =\text { total cost } \\ F & =\text { fitness function } \\ g_{0} & =\text { gravitational constant for Earth } \\ I_{s p} & =\text { specific impulse } \\ L_{c} & =\text { cone length } \\ L_{f, 1,2} & =\text { fuel tank length for stage } 1 \text { and } 2 \\ L_{o, 1,2} & =\text { oxidizer tank length for stage } 1 \text { and } 2 \\ L_{r} & =\text { rocket length } \\ m & =\text { wet mass } \\ m_{0} & =\text { initial wet mass } \\ m_{e n g i n e} & =\text { engine mass } \\ m_{f} & =\text { fuel mass } \\ m_{o x} & =\text { oxidizer mass } \\ m_{p} & =\text { payload mass }\end{array}$

\footnotetext{
Graduate Student, Department of Aeronautics and Astronautics, 37-348, AIAA Student Member, bairstow@mit.edu.

${ }^{\dagger}$ Asst Professor of Aero/Astro \& Engineering Systems, Department of Aeronautics and Astronautics, 33-410, AIAA Senior Member, deweck@mit.edu.

ॠ Senior Research Scientist, Computation Structures and Materials Branch, AIAA Fellow, xsobieskix@aol.com.
} 


\begin{tabular}{|c|c|c|}
\hline$m_{S S}$ & $=$ & Space Shuttle engine mass \\
\hline$m_{\text {struct }}$ & $=$ & structures mass \\
\hline$n_{d o m}$ & $=$ & number of times an individual is dominated \\
\hline$p$ & $=$ & fitness penalty from altitude \\
\hline$r$ & $=$ & radial position \\
\hline$R_{f}$ & $=$ & fuel tank radius \\
\hline$R_{o}$ & $=$ & oxidizer tank radius \\
\hline$R_{r}$ & $=$ & rocket radius \\
\hline$T_{1} \ldots T_{5}$ & $=$ & thrust profile parameters \\
\hline$T_{\max }$ & $=$ & max thrust \\
\hline$T_{S S}$ & $=$ & Space Shuttle max thrust \\
\hline$t_{f, 1,2}$ & $=$ & fuel tank thickness for stage 1 and 2 \\
\hline$t_{o, 1,2}$ & $=$ & oxidizer tank thickness for stage 1 and 2 \\
\hline$t_{r}$ & $=$ & rocket shell thickness \\
\hline$v$ & $=$ & total velocity \\
\hline$V_{f, 1,2}$ & $=$ & fuel tank volume for stage 1 and 2 \\
\hline$V_{o, 1,2}$ & $=$ & oxidizer tank volume for stage 1 and 2 \\
\hline$\alpha$ & $=$ & thrust vector deviation from normal \\
\hline$\alpha_{1}, \alpha_{2}$ & $=$ & thrust angle profile parameters \\
\hline$v_{a}$ & $=$ & first axial mode frequency \\
\hline$v_{b}$ & $=$ & first bending mode frequency \\
\hline$\mu$ & $=$ & standard gravitational parameter for Earth \\
\hline$\theta$ & $=$ & longitude \\
\hline$\theta_{c}$ & $=$ & cone half-angle \\
\hline$\rho$ & $=$ & atmospheric density \\
\hline$\rho_{a l}$ & $=$ & aluminum density \\
\hline$\rho_{f}$ & $=$ & fuel density \\
\hline$\rho_{o}$ & $=$ & oxidizer density \\
\hline$\rho_{t i}$ & $=$ & titanium density \\
\hline
\end{tabular}

\section{Introduction}

$\mathrm{T}$

HE value delivered by a rocket is the safe transfer of payload to orbit. In this case the orbit has been defined as a circular Low-Earth Orbit (LEO) at an altitude of $400 \mathrm{~km}$, but this can be adjusted based on mission needs.

Increasing the payload capability of a rocket is desirable. This will enable new mission concepts such as larger space telescopes or more capable Mars rovers. It will also reduce mission cost, because if there is a mass surplus, then cheaper materials can be used. In addition, the engineering cost will be reduced, since the mass budget is less difficult to balance. From the point of view of a rocket manufacturer, increasing rocket capability could potentially increase demand, which will increase profits.

Decreasing the cost of a rocket is also desirable and mission-enabling. Lowering program costs makes it easier for NASA to get approval from Congress. Commercial aspects of space such as communication satellites and space tourism become more appealing when launch costs drop. From a rocket manufacturer outlook, decreasing manufacturing costs will increase net profit, or increase demand if the savings are passed on to the consumer.

With these facts in mind, we would like to optimize rockets to increase payload mass and decrease cost at the same time. This is formally stated in Eq. (1) and Eq. (2).

$$
\begin{gathered}
\text { Maximize } \mathrm{J}_{1}=\text { Payload Mass (metric tons) } \\
\text { Minimize } \mathrm{J}_{2}=\text { Cost }(\$)
\end{gathered}
$$

Several studies have been conducted on system-level rocket optimization. ${ }^{1-3}$ These studies typically take a set payload mass, and optimize by minimizing the rocket gross mass. This paper takes a different approach by performing a multiobjective optimization, with payload as one of the objective functions. This leads to a survey of the design space rather than a specific design, and has its own benefits. 
Work by Schuman explored the advantages of including optimization in the design process by comparing concurrent design of the Space Shuttle external fuel tank with and without optimization as a tool. ${ }^{4}$ The results showed slight improvement when including optimization, but this led to a hypothesis that a more difficult design problem might have a more conclusive result. This model serves as a more complicated design problem, and also as a benchmark problem for future research in optimization algorithms.

\section{Model}

The model was built largely from first principles, and started as a single-stage liquid rocket. Previous work was used as a starting point, which influenced the structures and propulsion design significantly. ${ }^{5}$ The cost model was adapted from a simplified Space Shuttle external fuel tank cost model. ${ }^{6}$

The basic model structure of the single stage liquid rocket is depicted in the left side of Fig. 1. The rocket has a cylindrical body and is capped with a cone. The rocket dimensions are determined by the radius $\mathrm{R}_{\mathrm{r}}$ and the length of the propellant tanks. The propellant tanks hold the oxidizer and fuel, and are cylinders capped with hemispheres. The denser oxidizer is placed on top because this allows a greater control torque from gimbaling the engine, though that effect is not modeled in the current system.
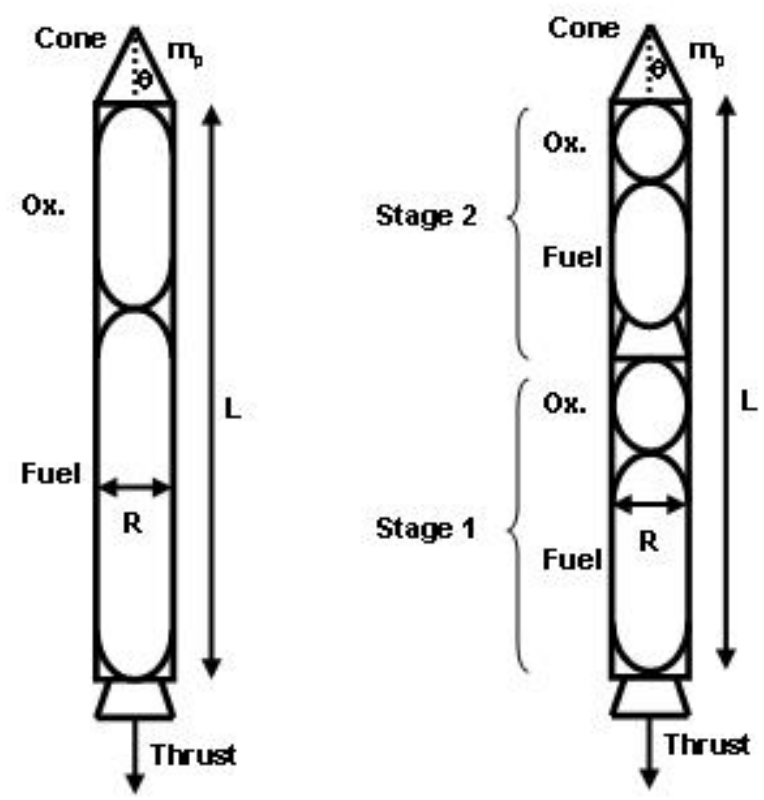

Figure 1. One-stage and two-stage rocket diagrams.

The single-stage model was expanded into a two-stage model (depicted in the right half of Figure 1) by treating the second stage as the payload of the first stage and applying the single-stage model twice. At a certain altitude, the rocket drops the first stage tanks and engine, and the model uses the ending conditions of the first stage as the initial conditions for the second stage. These conditions include velocity, position, and mass.

As stated previously, there are two objective outputs from the model: payload mass and cost. The payload mass should be maximized and the cost minimized. There are three more outputs that act as constraints, the ending altitude and the frequencies of the first axial and bending modes of vibration. There are fifteen inputs to the system which comprise the design vector. These design variables are the initial wet mass, the rocket radius, the cone halfangle, five parameters describing the thrust profile, two parameters describing the thrust-angle profile, the altitude at which to stage, the propellant types to use in stage one and stage two, and the structural materials used in the rocket body and tanks. The objectives, constraints, and design variables are included in the master table in Table 1 . The master table also includes a list of dependent variables that are used internally in the model, and a list of parameters which remain constant. 
Table 1. Master table of variables and parameters.

\begin{tabular}{|c|c|c|c|}
\hline Name & Symbol & Unit & Description \\
\hline \multicolumn{4}{|l|}{ Objectives } \\
\hline payload mass & $m_{p}$ & {$[\mathrm{~kg}]$} & objective \\
\hline cost & $\mathrm{C}$ & {$[\$]$} & objective \\
\hline \multicolumn{4}{|l|}{ Constraint Outputs } \\
\hline ending altitude & $A_{\text {final }}$ & {$[\mathrm{km}]$} & constraint \\
\hline axial mode freq. & $v_{a}$ & {$[\mathrm{~Hz}]$} & constraint \\
\hline bending mode freq. & $v_{b}$ & {$[\mathrm{~Hz}]$} & constraint \\
\hline \multicolumn{4}{|l|}{ Design Vector } \\
\hline initial wet mass & $m_{0}$ & {$[\mathrm{~kg}]$} & design variable \\
\hline rocket radius & $\mathrm{R}_{\mathrm{r}}$ & {$[\mathrm{m}]$} & design variable \\
\hline cone half-angle & $\theta_{\mathrm{c}}$ & [rad] & design variable \\
\hline thrust profile & $\mathrm{T}_{1} \ldots \mathrm{T}_{5}$ & {$[\mathrm{~N}]$} & design variable \\
\hline angle profile & $\mathrm{ca}_{1}, \mathrm{ca}_{2}$ & - & design variable \\
\hline staging altitude & A $_{\text {stage }}$ & {$[\mathrm{km}]$} & design variable \\
\hline fuel type - stage 1 & & - & design variable \\
\hline fuel type - stage 2 & & - & design variable \\
\hline structure material & & - & design variable \\
\hline tank material & & - & design variable \\
\hline \multicolumn{4}{|l|}{ Rocket Dimensions } \\
\hline length & $L_{r}$ & {$[\mathrm{~m}]$} & dependent \\
\hline thickness & $t_{r}$ & {$[\mathrm{~m}]$} & dependent \\
\hline cone height & $L_{c}$ & {$[\mathrm{~m}]$} & dependent \\
\hline \multicolumn{4}{|c|}{ Oxidizer Tank Dimensions } \\
\hline radius & $\mathrm{R}_{0}$ & {$[\mathrm{~m}]$} & dependent \\
\hline length & $\mathrm{L}_{0,1,2}$ & {$[\mathrm{~m}]$} & dependent \\
\hline thickness & $t_{0,1,2}$ & {$[\mathrm{~m}]$} & dependent \\
\hline oxidizer volume & $\mathrm{V}_{0,1,2}$ & {$\left[\mathrm{~m}^{3}\right]$} & dependent \\
\hline \multicolumn{4}{|c|}{ Fuel Tank Dimensions } \\
\hline radius & $\mathrm{R}_{\mathrm{f}}$ & {$[\mathrm{m}]$} & dependent \\
\hline length & $L_{f, 1,2}$ & {$[\mathrm{~m}]$} & dependent \\
\hline thickness & $t_{f, 1,2}$ & {$[\mathrm{~m}]$} & dependent \\
\hline fuel volume & $V_{f, 1,2}$ & {$\left[\mathrm{~m}^{3}\right]$} & dependent \\
\hline \multicolumn{4}{|l|}{ Parameters } \\
\hline air density & $\rho$ & {$\left[\mathrm{kg} / \mathrm{m}^{3}\right]$} & parameter \\
\hline oxidizer density & $\rho_{0}$ & {$\left[\mathrm{~kg} / \mathrm{m}^{3}\right]$} & parameter \\
\hline fuel density & $\rho_{f}$ & {$\left[\mathrm{~kg} / \mathrm{m}^{3}\right]$} & parameter \\
\hline aluminum density & $\rho_{\mathrm{al}}$ & {$\left[\mathrm{kg} / \mathrm{m}^{3}\right]$} & parameter \\
\hline titanium density & $\rho_{\mathrm{ti}}$ & {$\left[\mathrm{kg} / \mathrm{m}^{3}\right]$} & parameter \\
\hline orbit altitude & $A_{\text {target }}$ & {$[\mathrm{km}]$} & parameter \\
\hline initial inclination & $\theta_{0}$ & [rad] & parameter \\
\hline final inclination & $\theta_{\mathrm{f}}$ & {$[\mathrm{rad}]$} & parameter \\
\hline
\end{tabular}

The thrust parameters $T_{1}, T_{2}, T_{3}, T_{4}$, and $T_{5}$ define the thrust at $0 \mathrm{~km}, 50 \mathrm{~km}, 100 \mathrm{~km}, 200 \mathrm{~km}$, and $400 \mathrm{~km}$ altitudes, respectively. In between these altitudes the thrust is interpolated linearly. However, this approach could be adapted to use a spline instead of a simple linear interpolation. Initially the model used an exponentially decaying thrust, but this did not capture all of the characteristics of typical actual thrust profiles. ${ }^{7,8}$ A sample thrust profile from the model follows in Figure 2.

The thrust angle parameter variables $\alpha_{1}$ and $\alpha_{2}$ define the angle (with respect to a normal from the Earth's surface) of the thrust vector over the course of the trajectory. $\alpha_{1}$ is the altitude in km to start turning the rocket, while $\alpha_{2}$ specifies the additional altitude over which to complete the turn. If the altitude is less than $\alpha_{1}$ then the angle is zero, and if it is greater than $\alpha_{1}+\alpha_{2}$ then the angle is $\pi / 2$. If it is in between then it is defined by Eq. (3).

$$
\text { angle } \left.=\left[1-\cos \left(\pi^{*}\left(\mathrm{~A}-\alpha_{1}\right) / \alpha_{2}\right)\right)\right]^{* \pi / 4}
$$

A picture of the thrust angle profile for $\alpha_{1}=100 \mathrm{~km}$ and $\alpha_{2}=200 \mathrm{~km}$ is shown in Figure 3 . 


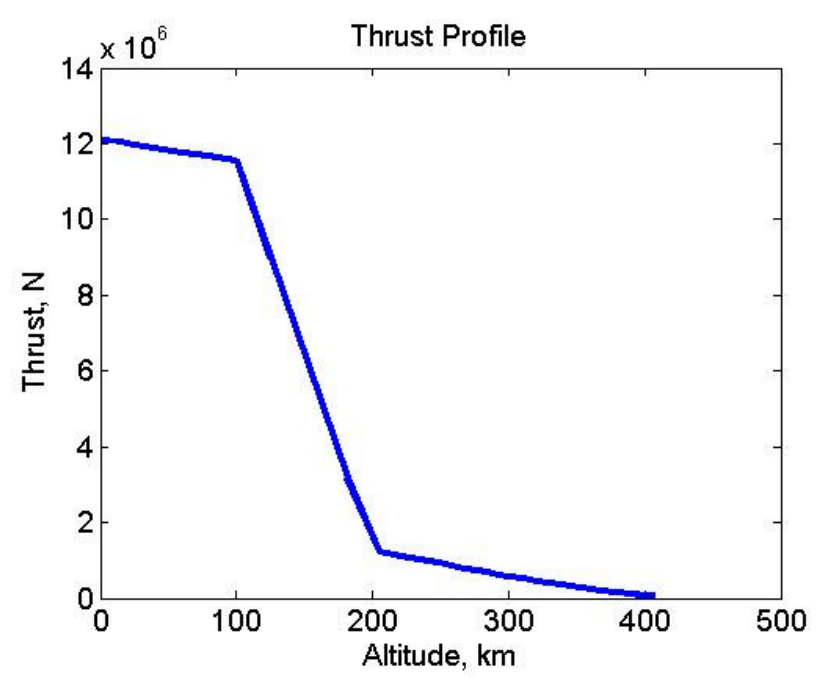

Figure 2. Sample thrust profile.

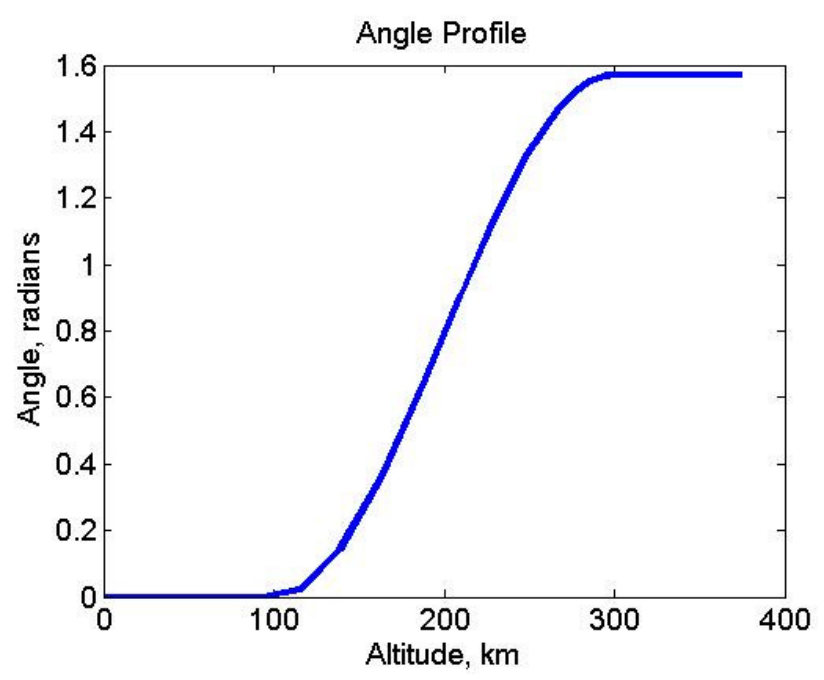

Figure 3. Sample thrust angle profile.

The model is divided into several subsystems, and the flow of design variables is displayed as an $\mathrm{N}^{2}$ diagram (design dependency matrix) in Table 2. Outputs from a subsystem are shown to the left and right, and inputs to a subsystem are in the cells above and below.

Table 2. $\mathrm{N}^{2}$ diagram.

\begin{tabular}{|c|c|c|c|c|c|c|c|}
\hline Inputs & $\theta_{\mathrm{c}} \mathrm{R}_{\mathrm{r}}$ & \begin{tabular}{|l|}
$\mathrm{m}_{\text {wet }}, \mathrm{T}$, \\
$\alpha, \mathrm{R}_{\mathrm{r}}$, \\
$\mathrm{A}_{\text {stage }}$, \\
prop. type \\
\end{tabular} & $\begin{array}{l}\text { prop. } \\
\text { type }\end{array}$ & $\begin{array}{l}\mathrm{R}_{\mathrm{r}}, \\
\text { material } \\
\text { type }\end{array}$ & $\mathrm{m}_{\text {wet }}$ & $\begin{array}{l}\mathrm{R}_{\mathrm{r}}, \text { prop. } \\
\text { type, material } \\
\text { type }\end{array}$ & \\
\hline & Aero & $\overline{C_{D}}$ & & $\mathrm{~L}_{\mathrm{c}}, \mathrm{C}_{\mathrm{D}}$ & & $\mathrm{L}_{\mathrm{c}}$ & \\
\hline & & Traj & $\begin{array}{l}m_{\text {prop }} \\
T_{\max }\end{array}$ & $\mathrm{v}_{\max }, \mathrm{q}_{\max }$ & $\begin{array}{l}\mathrm{A}_{\text {final }}, \text { ending } \\
\text { conditions }\end{array}$ & & $\mathrm{A}_{\text {final }}$ \\
\hline & & & Prop & $\begin{array}{l}\mathrm{m}_{\mathrm{f}}, \mathrm{m}_{\mathrm{o}} \\
\mathrm{m}_{\mathrm{eng}}\end{array}$ & $\mathrm{m}_{\mathrm{f}}, \mathrm{m}_{\mathrm{o}}$ & & \\
\hline & & & & Struct & $m_{\text {struct, }} v_{a}, v_{b}$ & $\begin{array}{l}\text { geometry, } \\
\text { masses }\end{array}$ & $v_{a}, v_{b}$ \\
\hline & & $\begin{array}{l}\mathrm{m}_{\text {payload }} \\
1^{\text {st }} \text { stage } \\
\text { conditions }\end{array}$ & & & System & & $m_{\text {payload }}$ \\
\hline & & & & & & Cost & $\$$ \\
\hline & & & & & & & Output \\
\hline
\end{tabular}

The design vector is output by the inputs box, and distributed to the necessary subsystems. The aerodynamics subsystem calculates the cone length via geometry, and calculates an estimate of the coefficient of drag using the simple pressure drag equation shown in Eq. (4). This estimate is only used for premliminary calculations; a more complicated model is used later to account for the effects of Mach number.

$$
\mathrm{C}_{\mathrm{D}}=2 * \sin \left(\theta_{\mathrm{c}}\right)^{2}
$$


The trajectory subsystem takes in several inputs and calculates the fuel usage and final altitude via the shooting method. It uses the ODE (shown in Eq. (5-9)) with a state vector composed of radial position, radial velocity, longitude, angular velocity, and mass. The model calculates the changes in velocity using the thrust, gravity, and drag applied at the correct angles. Changes in mass are calculated as decreasing according to thrust level and Isp. The air density and temperature numbers come from the 1962 US Standard Atmosphere model. ${ }^{9}$

$$
\begin{gathered}
\mathrm{d} / \mathrm{dt}[\mathrm{r}]=\mathrm{r}^{\prime} \\
\mathrm{d} / \mathrm{dt}\left[\mathrm{r}^{\prime}\right]=-10^{9} * \mu / \mathrm{r}^{2}+\mathrm{r}^{*} \theta^{2}+\left(\mathrm{T}\left[\mathrm{r}, \mathrm{T}_{1} \ldots \mathrm{T}_{5}\right]-\mathrm{D}\left[\mathrm{r}, \mathrm{v}, \theta_{\mathrm{c}}, \mathrm{R}_{\mathrm{r}}\right]\right) * \cos \left(\alpha\left[\mathrm{r}, \alpha_{1} \ldots \alpha_{5}\right]\right) / \mathrm{m} \\
\mathrm{d} / \mathrm{dt}[\theta]=\theta^{\prime} \\
\mathrm{d} / \mathrm{dt}\left[\theta^{\prime}\right]=\left(\mathrm{T}\left[\mathrm{r}, \mathrm{T}_{1} \ldots \mathrm{T}_{5}\right]-\mathrm{D}\left[\mathrm{r}, \mathrm{v}, \theta_{\mathrm{c}}, \mathrm{R}_{\mathrm{r}}\right]\right) * \sin \left(\alpha\left[\mathrm{r}, \alpha_{1} \ldots \alpha_{5}\right]\right) /(\mathrm{r} * \mathrm{~m}) \\
\left.\mathrm{d} / \mathrm{dt}[\mathrm{m}]=-\mathrm{T}\left[\mathrm{r}, \mathrm{T}_{1} \ldots \mathrm{T}_{5}\right] /\left(\mathrm{I}_{\mathrm{sp}} * \mathrm{~g}_{0}\right)\right]
\end{gathered}
$$

The propulsion subsystem inputs the mass of propellant from the trajectory subsystem, divides this mass up into oxidizer and fuel, and adds an ullage penalty. It also calculates the mass of the engine by scaling the Space Shuttle engine with max thrust according to Eq. (10). ${ }^{5}$ Engine nozzle efficiency was not taken into account at different altitudes.

$$
\mathrm{m}_{\text {engine }}=\mathrm{T}_{\max } * \mathrm{~m}_{\mathrm{SS}} / \mathrm{T}_{\mathrm{SS}}
$$

The structures subsystem inputs the propellant masses and some drag quantities. It then sizes the propellant tanks to hold the propellant, and the rocket length to hold the tanks. Structural thicknesses are calculated based on loadings conditions. The tanks are sized to hold propellant at the necessary pressure, while the rocket structures are sized to withstand the thrust and drag loads from the point of maximum dynamic pressure, $\mathrm{q}_{\max }$.

The cost subsystem calculates the cost for both materials and manufacturing. The material costs are based on material masses and engine mass. The engine is the largest of the material dry masses, and has the highest cost per kilogram, so it makes up the bulk of the material cost. The manufacturing cost is based on seam lengths. The cost parameters include cost per meter of seam and cost per $\mathrm{kg}$ of material. These parameters were taken from an external fuel tank model and have been scaled to produce numbers in the expected amounts. ${ }^{6,10}$

Finally, the costs are summed and the payload mass is calculated according to Eq. (11). Since the wet mass was an input, the mass that was not used up as fuel or taken up by structures is the available payload mass.

$$
\mathrm{m}_{\mathrm{p}}=\mathrm{m}-\mathrm{m}_{\text {struct }}-\mathrm{m}_{\mathrm{ox}}-\mathrm{m}_{\mathrm{f}}
$$

The staging is handled by performing the rocket calculations twice in succession. While performing calculations for the first stage, the second stage is treated as payload. The calculations take place as normal for a single-stage rocket with staging altitude as the target altitude for the first stage. After the defined staging altitude is reached the payload mass is noted, and is used as the wet mass for the second stage of the rocket. Thus the model returns to the trajectory subsystem and uses all the ending conditions from the first stage as the beginning conditions for the second stage. The same set of calculations is performed again from the staging altitude to the final altitude, and the remaining payload is output as the final payload mass.

Note that there is little coupling between the subsystems in the model. The only feedback is the second loop of calculations for the second stage, but even this is designed so that the second stage does not impact the first stage. Thus there is no iteration required; this implementation was chosen to allow this for faster evaluation of design vectors.

The model was benchmarked against five existing rockets from the Delta line. ${ }^{10}$ These comparisons were done for a launch from Cape Canaveral at $28.5^{\circ}$ inclination to the space station orbit at $407 \mathrm{~km}$ altitude, $51.6^{\circ}$ inclination. The wet masses, rocket radii, cone angles, initial thrusts, and propellant types from the rockets were entered into the model. The other flight characteristics were varied until the rocket reached the correct altitude. Then the payload masses and costs from the model were compared to the actual values, and the results are shown in Table 3 . 
Table 3. Benchmarking results

\begin{tabular}{|c|c|c|c|c|c|c|c|c|c|}
\hline Rocket Type & \begin{tabular}{|l|} 
Actual \\
Payload \\
Mass (kg) ${ }^{5}$ \\
\end{tabular} & \begin{tabular}{|l|} 
Calc. \\
Payload \\
Mass (kg) \\
\end{tabular} & \begin{tabular}{|l}
$\%$ \\
Error \\
\end{tabular} & \begin{tabular}{|l|} 
Actual \\
Cost \\
$(\$ \mathbf{M})^{5}$ \\
\end{tabular} & $\begin{array}{l}\text { Calc. } \\
\text { Cost } \\
(\$ M) \\
\end{array}$ & \begin{tabular}{|l|}
$\%$ \\
Error
\end{tabular} & \begin{tabular}{|l|} 
Actual \\
$\mathrm{m}_{\mathrm{p}} / \mathrm{C}$ \\
$(\mathrm{kg} / \mathbf{\$ M})^{5}$ \\
\end{tabular} & \begin{tabular}{|l|} 
Calc. \\
$\mathrm{m}_{\mathrm{p}} / \mathrm{C}$ \\
$(\mathrm{kg} / \$ \mathrm{M})$ \\
\end{tabular} & $\begin{array}{l}\% \\
\text { Error } \\
\end{array}$ \\
\hline $\begin{array}{l}\text { Delta II 7326- } \\
10\end{array}$ & 2294 & 2700 & 17.70 & 43.5 & 41.3 & -5.06 & 52.74 & 65.38 & 23.97 \\
\hline $\begin{array}{l}\text { Delta II 7925- } \\
10\end{array}$ & 4104 & 3500 & -14.72 & 55 & 52.5 & -4.55 & 74.62 & 66.67 & -10.66 \\
\hline \begin{tabular}{|ll} 
Delta & IV \\
Medium & \\
\end{tabular} & 8501 & 9990 & 17.52 & 72.6 & 70.1 & -3.44 & 117.09 & 142.51 & 21.71 \\
\hline $\begin{array}{lr}\text { Delta } & \text { IV } \\
\text { Medium+ } & (4,2)\end{array}$ & 11455 & 13800 & 20.47 & 98 & 93.8 & -4.29 & 116.89 & 147.12 & 25.87 \\
\hline $\begin{array}{ll}\text { Delta } & \text { IV } \\
\text { Heavy } & \end{array}$ & 21892 & 24500 & 11.91 & 150 & 162.3 & 8.20 & 145.95 & 150.96 & 3.43 \\
\hline
\end{tabular}

The payload masses calculated had a 10-20\% error with respect to the benchmark. The error was not completely systematic, however, since the results for the Delta II 7925-10 simulation underestimated the payload mass, while the others overestimated. One caveat is that each of these rockets besides the Delta IV Medium uses solid rocket boosters, and the model is not built to handle solid rockets or multiple stages acting in parallel. For the cost estimation, the model is typically low by about $5 \%$. Since the model cost model just works by scaling rocket material cost, manufacturing cost, and engine cost, this suggests that the scaling is simply set slightly too low for the lower range of rockets, but overestimates for larger rockets. Also, the Delta rocket costs are the costs to purchase a rocket, so they have a profit added on to the actual rocket cost, which this model does not cover. The mass per cost errors are of slightly higher magnitude, since the mass and cost errors compound for most cases. This benchmarking analysis suggests that the model produces reasonable results for payload masses and costs.

\section{Optimization Method}

In order to populate a Pareto front, a multi-objective genetic algorithm (MOGA) was used. ${ }^{11}$ This heuristic technique was chosen because discrete design variables such as material type and propellant type were used, and genetic algorithms handle discrete variables well. The two objectives were to maximize $\mathrm{J}_{1}$ (payload mass) and minimize $\mathrm{J}_{2}$ (cost).

The code used was adapted from work by Schuman. ${ }^{4}$ Each optimization run typically used a population size of 100 members, and a run length of 100 generations. The fitness function initialized at a maximum of 1 for each individual. Then it gave a small penalty of 0.01 to each design for each other design that dominated it by having a lower cost and higher payload capability. It also gave a penalty if the ending altitude was less than $400 \mathrm{~km}$. The fitness was then squared to increase the gap between the more and less dominated designs. Finally, it gave zero fitness for designs that were otherwise infeasible. This fitness value was then used to decide which designs carried on to the next generation of the genetic algorithm. The fitness function for a feasible point is shown in Eq. (12).

$$
\mathrm{F}=\max \left\{1.0-0.01 * \mathrm{n}_{\text {dom }}-\mathrm{p}\left(\mathrm{A}_{\text {final }}\right), 0\right\}^{2}
$$

A variable penalty shown in Eq. (13) was used for the altitude constraint. The further the constraint was violated, the more severe the penalty applied. The penalty curve steepened with each generation. This is because a low curve would not penalize the infeasible designs enough, but a high curve would often cause the entire starting population to have zero fitness. By starting with a low curve and raising it, the MOGA was able to find the largest number of feasible designs. Example penalty curves from the $10^{\text {th }}$ and $50^{\text {th }}$ generations are shown in Figure 4 . The lower curve is the $10^{\text {th }}$ generation curve, and the higher, stricter curve is the $50^{\text {th }}$ generation. If the penalty is greater than 1 , then 
the fitness bottoms out at 0 . This means that a penalty above the dotted line in Figure 4 would lead to an infeasible design.

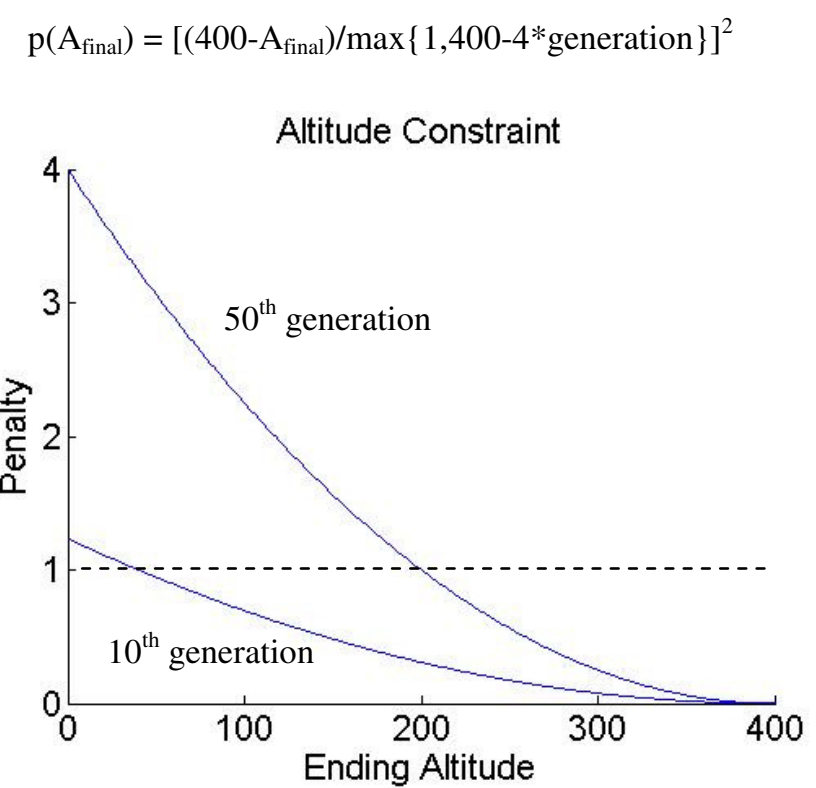

After each generation, individuals were chosen to mate for the next generation. Selection was done randomly and proportionally according to individual fitness. After individuals were chosen to survive, there was a chance for crossover and mutation during mating to produce the next generation. ${ }^{11}$

After completing a 100 population, 100 generation run with about a five minute run time, the code would build a Pareto front. When sorting for the Pareto optimal points, the code only considered points that had zero penalty for low altitude. From the remaining points it searched for the non-dominated solutions and plotted them.

Below are examples of the output from the genetic algorithm. Figure 5 shows all the feasible unpenalized design points from a 100 generation run. Typically of the 10,000 individuals, 2000-4000 will be feasible. Figure 6 shows the non-dominated solutions from the first plot. The utopia point is to the lower right, with high payload of 50.7 tons and low cost of 140.2 \$M. The utopia point combines the best instances of each objective function into a single point. $^{11}$

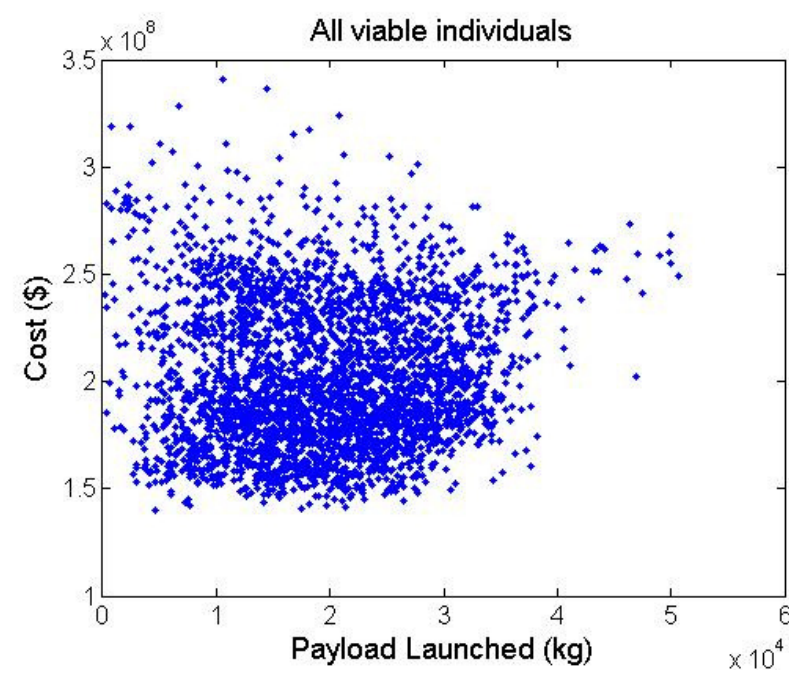

Figure 5. All feasible individuals

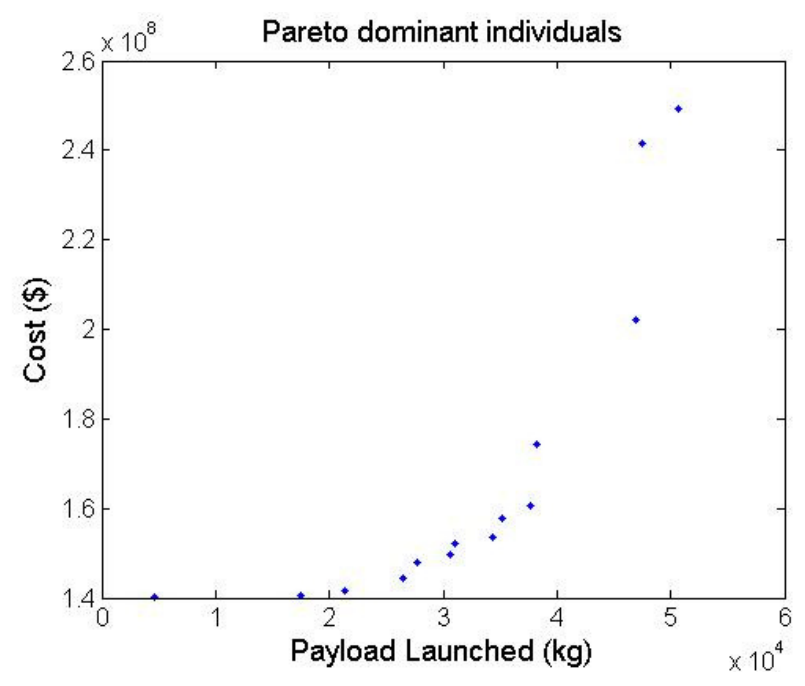

Figure 6. Non-dominated individuals

from a MOGA run.

Notice that the Pareto front made is not very well distributed and has a couple steps. Running the MOGA multiple times would lead to covering different ranges and help fill out the Pareto front. ${ }^{2}$ Also, the Pareto fronts 
made by successive runs would sometimes be closer or farther from the utopia point. Thus Pareto fronts from multiple runs were combined by collecting the non-dominated individuals from each run, and then comparing them and keeping only the individuals which remain non-dominated across the entire ensemble.

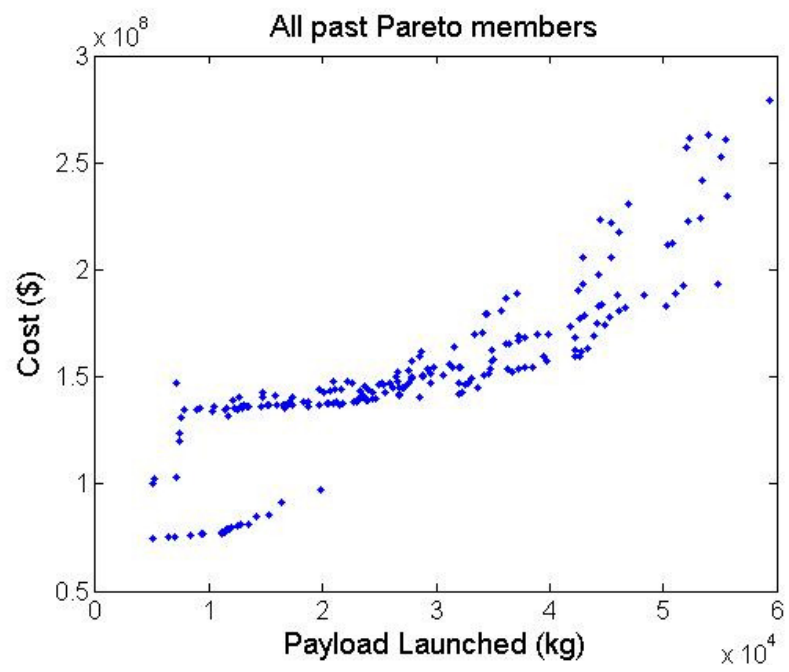

Figure 7. Compilation of ten Pareto fronts

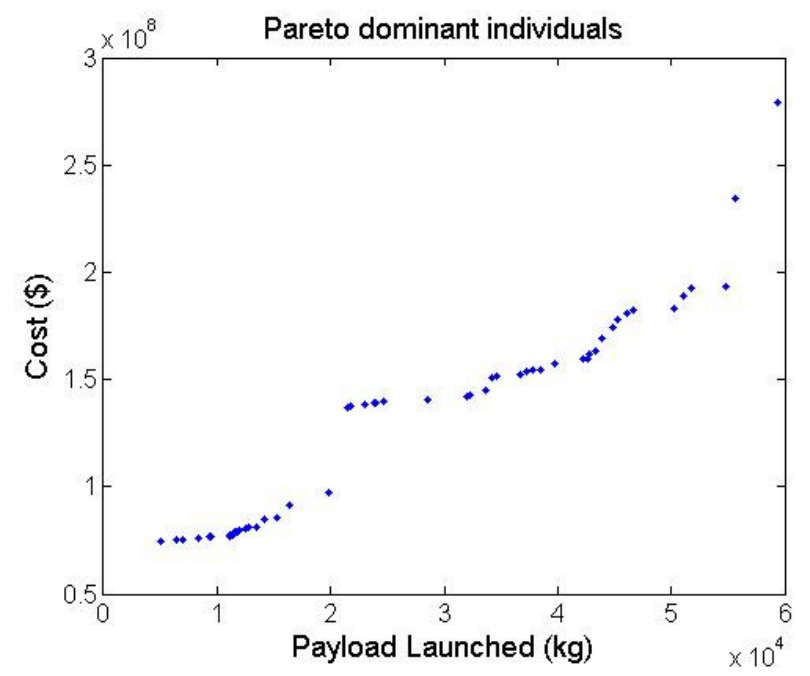

Figure 8. Non-dominated points from ten Pareto fronts

Figure 7 shows the Pareto fronts from ten separate runs all plotted together, and Figure 8 then treats the complication of ten fronts as the population from which to make a new Pareto front. From Figure 7 we see that many of the Pareto fronts are actually significantly sub-optimal. This is a result of the randomness inherent in a heuristic optimization algorithm, and suggests that more computation is necessary to give confidence with the results. Also, in Figure 8 we see that the front is still not very smooth, though the front from the compilation does look better than that from the single run. The code was run many more times while varying the seeding mechanism, crossover and mutation rates and the plots in Figure 9 and Figure 10 were produced.

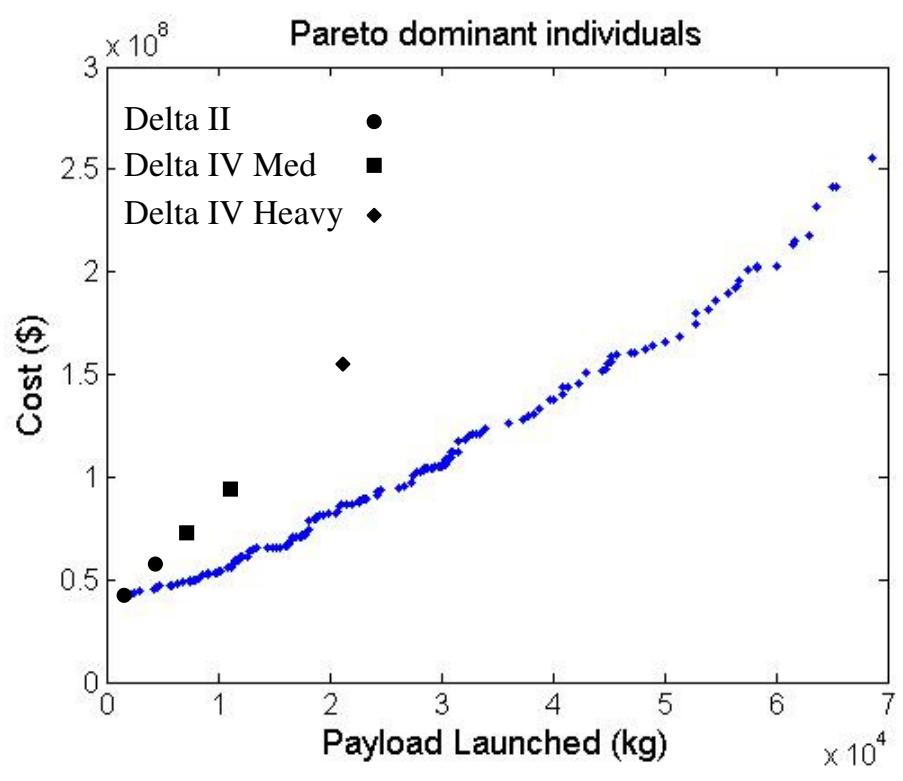

Figure 9. Non-dominated points from 720 Pareto fronts with benchmarking points plotted 


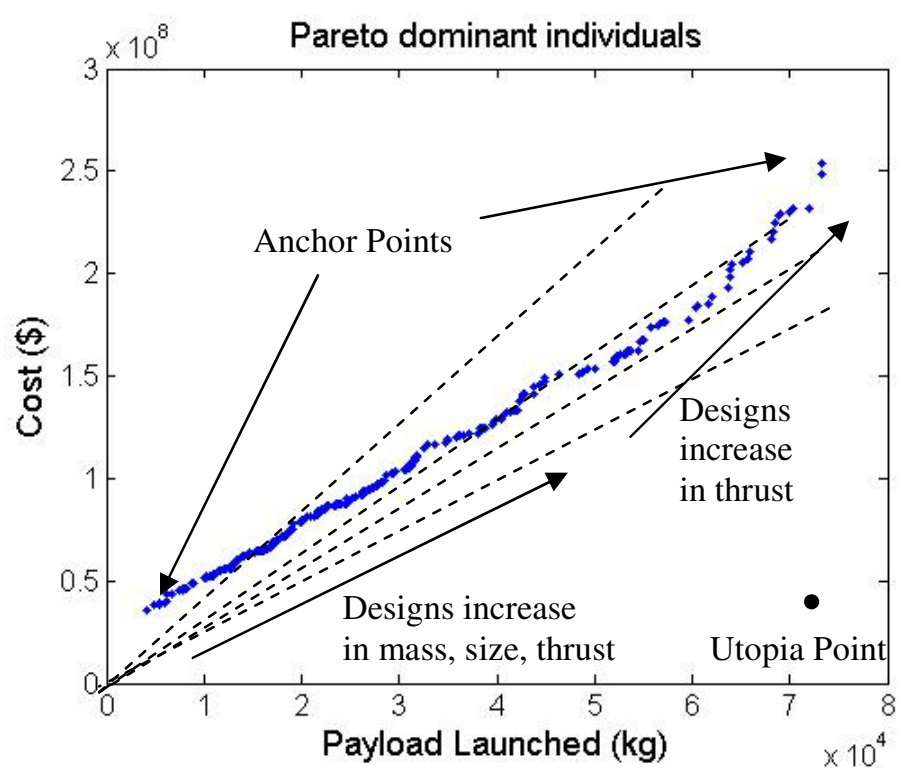

Figure 10. Non-dominated points from 1640 Pareto fronts

with payload/cost isolines

Figure 9 and Figure 10 show the Pareto fronts compiled from a progressively larger number of runs. After a few hundred runs, the Pareto front becomes well populated, and there are only minor bumps which could reflect real design changes or be indications that more computation is needed. Moving from 720 to 1640 optimization runs does not change the shape of the Pareto front significantly, but does shift the entire Pareto front slightly towards the utopia point of 73.3 tons and $35.5 \$ \mathrm{M}$. The Pareto front is very linear, which is likely a result of the cost model being simple and heavily driven by engine size.

In Figure 9 we see that the benchmark cases fall along a steeper line. One reason is that the benchmark points are for a different inclination and require a plane change maneuver which can be another $3 \mathrm{~km} / \mathrm{s}$ of delta $\mathrm{V}$, and thus a higher cost per payload slope is expected. The previous benchmarking analysis was a better apples-to-apples comparison, which is why the results seemed closer then. It is also possible that the optimizer simply finds better points in the model.

From Figure 10 we see the low cost and high payload mass anchor points. From those anchor points we can construct a normalized space with vertices $(0,0),(1,0),(0,1)$, and $(1,1) .(0,0)$ is the low cost anchor point, $(1,1)$ is the high payload anchor point, and $(1,0)$ is the normalized utopia point. From this utopia point we can find the closest design, hereafter referred to as the "best" design.

Figure 11 shows the normalized distance to the final utopia point as an increasing number of runs was performed. The Average line shows the progression of the average distance of each non-dominated point, while the Best line shows the distance of the closest point. The average distance tended to fall a little at a time, while the best distance tended to fall in jumps, which suggests a greater degree of randomness. After 1640 runs and about 150 hours of computation time, the distances do not seem to be bottomed out, so this suggests that the results would benefit from more computation. 


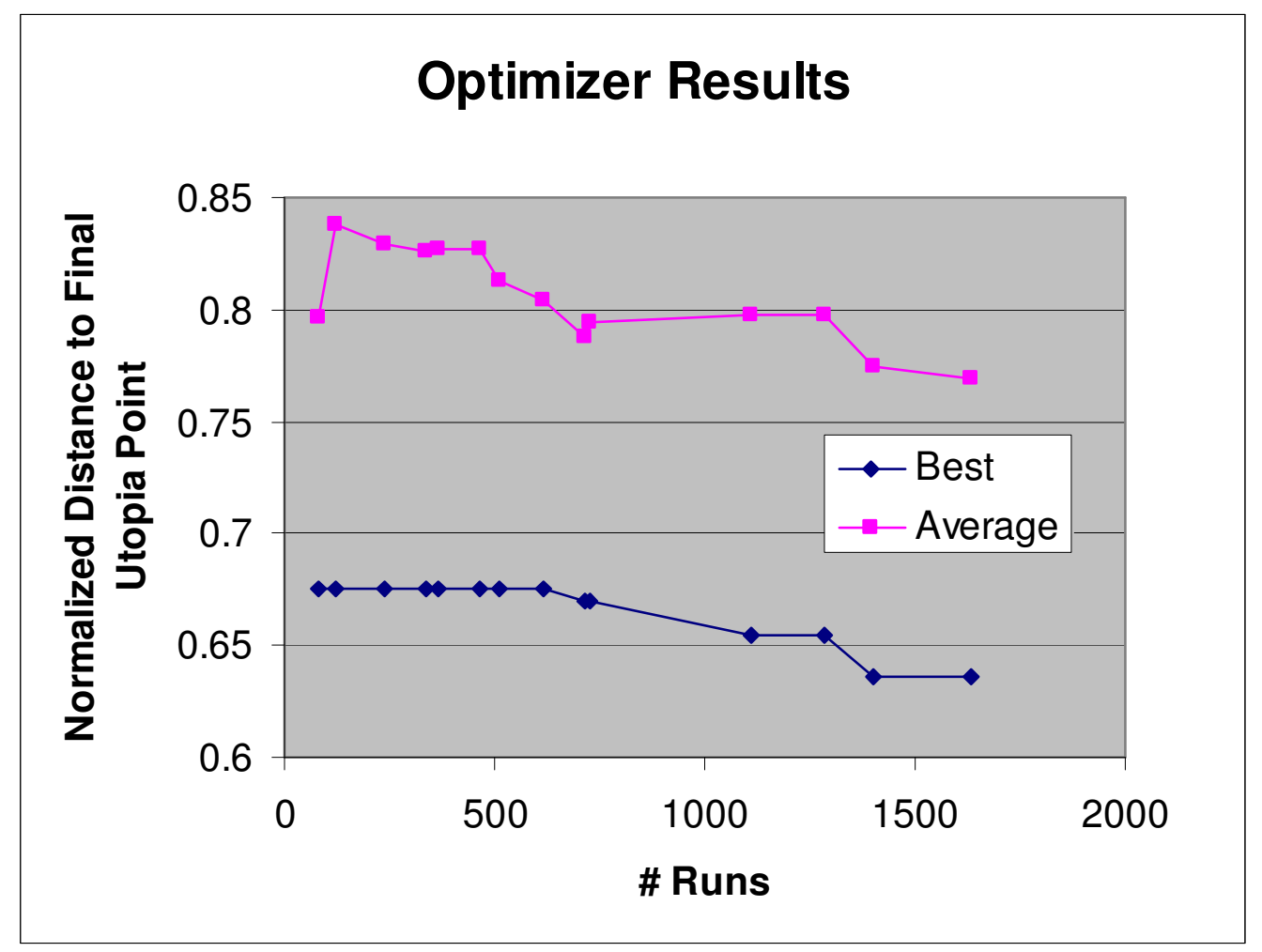

Figure 11. Distances to the final utopia point with an increasing number of runs

\section{Results}

It is useful to visualize point designs on the Pareto front to understand the outputs of the optimizer. Only one point will be shown here in full detail, though the anchor points will be described as well.

The low cost anchor point had a payload mass of $4200 \mathrm{~kg}$ and a cost of $35.5 \$ \mathrm{M}$. The design vector had a wet mass of 135 tons, a radius of $1.53 \mathrm{~m}$, and a cone half-angle of 0.15 radians. The thrust started at about $1.5 \mathrm{MN}$, increased a little until the rocket reached $50 \mathrm{~km}$ altitude, then started dropping evenly until $400 \mathrm{~km}$ was reached. The rocket began turning at about $50 \mathrm{~km}$ altitude, and finished turning at about $200 \mathrm{~km}$. The rocket was sized to be about $30 \mathrm{~m}$ long. Design points near the low end of the Pareto front used liquid oxygen / hydrazine propellant for the first stage, and liquid oxygen / liquid hydrogen propellant for the second stage. The hydrazine in the first stage has a higher density, so there is a trade between tank size and propulsive efficiency. It is common for the first stage of a rocket to use a denser fuel. ${ }^{10}$ All larger designs used only liquid oxygen / liquid hydrogen for the greater specific impulse, but lower density.

The "best" point design had a payload mass of $52100 \mathrm{~kg}$ and a cost of $157.3 \$ \mathrm{M}$. The design vector had a wet mass of 959 tons, a radius of $3.98 \mathrm{~m}$, and a cone half-angle of 0.11 radians. The rocket shape is shown in Figure 12 (dimensions are in meters), and the thrust and thrust angle profiles are shown in Figure 13 and Figure 14 respectively. This rocket is sized much larger, though it is fairly proportional to the low-cost design. In the second stage the fuel tanks are both spherical because the model sizes them as cylinders capped with hemispheres, and the lower limit is when the cylinder size goes to zero. This means the model ends up with fuel tanks with wasted space, which is inefficient, but not a problem with the optimizer. The thrust profile has a dip at $50 \mathrm{~km}$ altitude, which is a characteristic seen in realistic rocket profiles to avoid maximum dynamic pressure. ${ }^{8}$ Overall, the thrust profile is consistent with real thrust profiles, and came out purely from the optimization. This design is nearly up against the bounds for wet mass and cone half-angle at a maximum of 1000 tons and a minimum of 0.10 radians respectively.

In Figure 13 a sample representative thrust profile is plotted. ${ }^{8}$ This profile was scaled to have the same initial thrust for comparison. The sample profile has some of the same rough features as the profile found by the optimizer but is not exactly the same. 


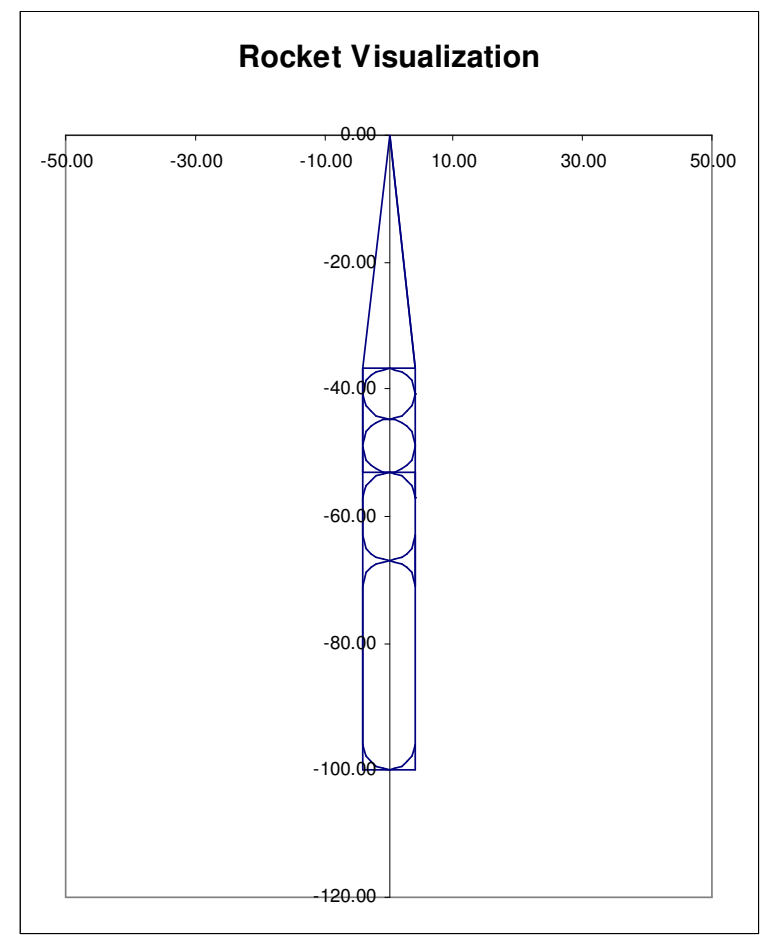

Figure 12. Rocket design for point

closest to utopia point

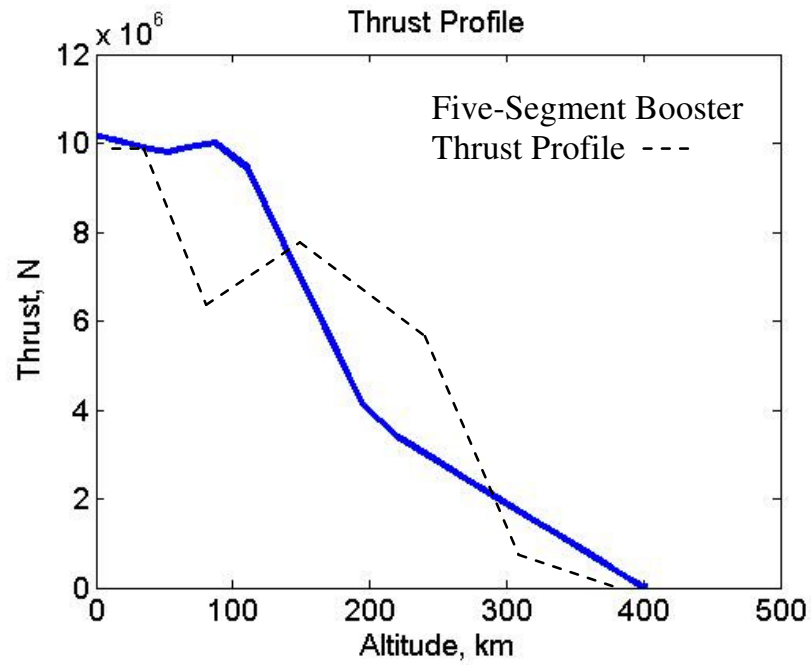

Figure 13. Thrust profile for "best" design

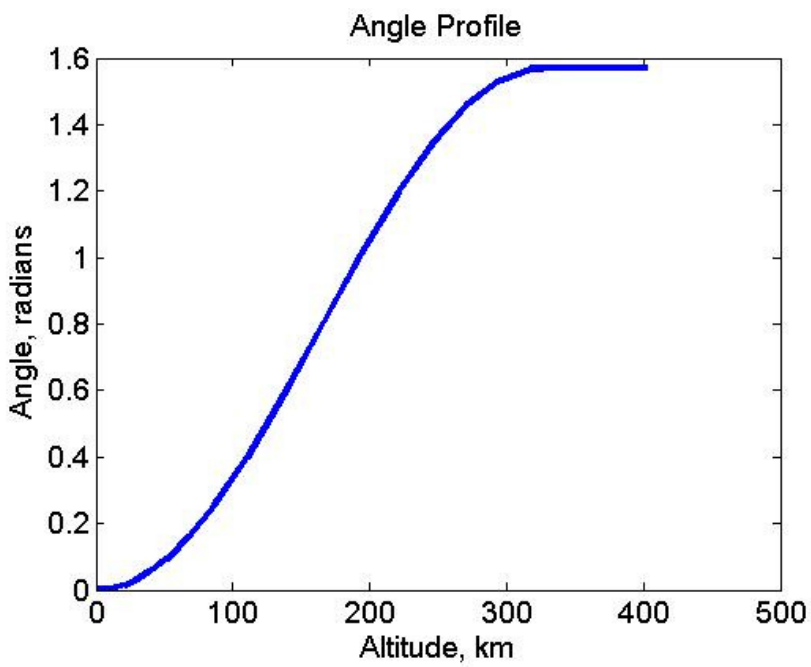

Figure 14. Thrust angle profile for "best" design

The high payload anchor point had a payload mass of $73300 \mathrm{~kg}$ and a cost of $254.1 \$ \mathrm{M}$. The design vector had a wet mass of 990 tons, a radius of $4.53 \mathrm{~m}$, and a cone half-angle of 0.12 radians. The thrust started at about $20 \mathrm{MN}$, had a pronounced dip to $15 \mathrm{MN}$ at $50 \mathrm{~km}$ altitude, increased back up to $18 \mathrm{MN}$ at $100 \mathrm{~km}$, then fell to nearly zero thrust from $200 \mathrm{~km}$ up to $400 \mathrm{~km}$. The rocket began turning immediately and finished turning at about $200 \mathrm{~km}$ altitude. The rocket was sized to be about $90 \mathrm{~m}$ long, which is actually shorter than the "best" design. This is because the "best" design was already near the maximum allowed wet mass, so in order to increase payload mass the optimizer had to increase thrust. Increasing thrust decreased the amount of flight time, and thus decreased the gravity losses, which led to less fuel and a smaller rocket with larger engines.

The characteristics of the low-cost, "best," and high-payload designs are summarized in Table 4, and the mass breakdowns are shown in Table 5. One characteristic which was constant throughout the Pareto front was that the staging altitude was near the final altitude of $400 \mathrm{~km}$. What this means is that with the model used, it was found best to use the first stage to reach altitude and the second stage to perform circularization of the orbit. This is similar to the role the S-IVB played in Apollo for the Saturn rocket. ${ }^{10}$ 
Table 4. Characteristics of anchor points and point closest to utopia point

\begin{tabular}{|l|r|r|r|}
\hline & \multicolumn{1}{|l|}{ lost-cost } & "Best" & High-payload \\
\hline Wet Mass (tons) & 134.8 & 958.8 & 990.1 \\
\hline Radius (m) & 1.53 & 3.98 & 4.53 \\
\hline Cone Half-Angle (rad) & 0.154 & 0.108 & 0.116 \\
\hline Thrust at 0 km (MN) & 1.53 & 10.2 & 19.2 \\
\hline Thrust at 50 km (MN) & 1.65 & 9.79 & 14.5 \\
\hline Thrust at 100 km (MN) & 1.28 & 10.1 & 19.1 \\
\hline Thrust at 200 km (MN) & 0.63 & 3.77 & 0.02 \\
\hline Thrust at 400 km (MN) & 0.03 & 0.003 & 0.006 \\
\hline Angle Param. 1 (km) & 56.9 & 0.40 & 0.34 \\
\hline Angle Param. 2 (km) & 177.4 & 327.1 & 212.7 \\
\hline Staging Altitude (km) & 396.5 & 396.9 & 396.7 \\
\hline Stage 1 Propellant & LOX/Hydrazine & LOX/LH $_{2}$ & LOX/LH \\
\hline Stage 2 Propellant & LOX/LH & LOX/LH $_{2}$ & LOX/LH \\
\hline Rocket Material & Aluminum & Aluminum & Aluminum \\
\hline \hline Tank Material & Aluminum & Aluminum & Aluminum \\
\hline Payload Mass (tons) & $\mathbf{4 . 2}$ & $\mathbf{5 2 . 1}$ & $\mathbf{7 3 . 3}$ \\
\hline Cost (\$M) & $\mathbf{3 5 . 5}$ & $\mathbf{1 5 7 . 3}$ & $\mathbf{2 5 4 . 1}$ \\
\hline
\end{tabular}

Table 5. Mass breakdowns for anchor points and point closest to utopia point

\begin{tabular}{|l|r|r|r|}
\hline Mass (kg) & Low-cost & "Best" & High-payload \\
\hline Structures & 200 & 2000 & 3100 \\
\hline Engine & 3300 & 19800 & 37100 \\
\hline Fuel & 63000 & 126100 & 124700 \\
\hline Oxidizer & 63800 & 756700 & 748100 \\
\hline Payload & 4200 & 52100 & 73300 \\
\hline Total & 134800 & 958800 & 990100 \\
\hline \hline
\end{tabular}

\section{Sensitivity Analysis}

A sensitivity analysis was carried out by making small perturbations in parameters from the "best" design point, and examining the effects on the payload mass and cost. The sensitivities shown are normalized by taking the gradient and dividing by magnitude according to Eq. (14). The results are shown in Figure 15 to Figure 18. The positive delta is for a $0.1 \%$ positive perturbation, and the negative delta is for a $0.1 \%$ negative perturbation.

Normalized Sensitivity $=\Delta \%$ performance $/ \Delta \%$ variation 


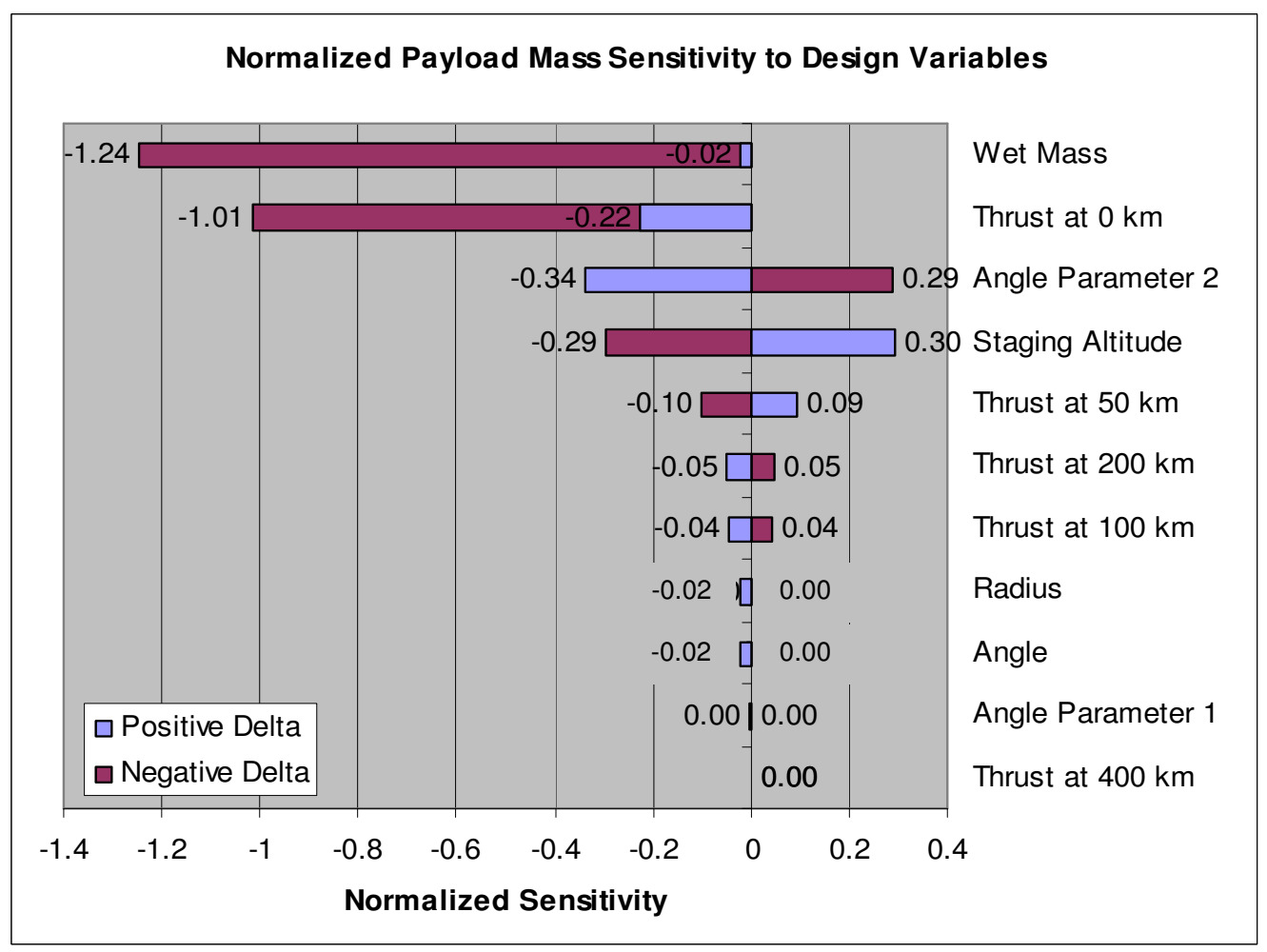

Figure 15. Normalized sensitivity of payload mass to design variables

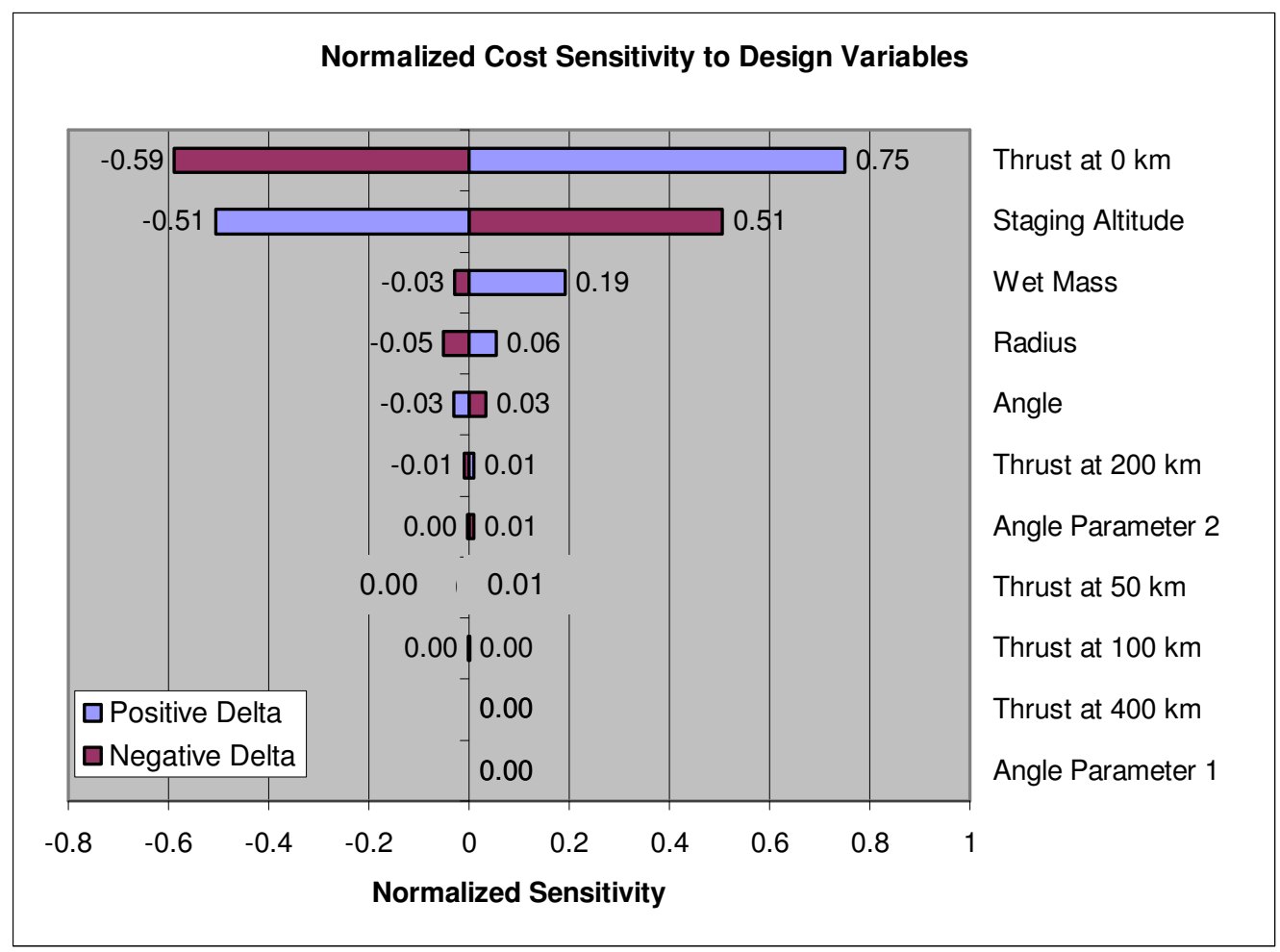

Figure 16. Normalized sensitivity of cost to design variables 
Figure 15 shows the sensitivity of the payload mass to the input variables, while Figure 16 shows the sensitivity of the cost. The payload mass was most sensitive to the initial wet mass. This is because the calculated payload is the wet mass less the structures and propellant masses, so there is a direct relationship. Notice that changing the wet mass or thrust in either direction decreases the payload mass, which suggests they are at a local maximum. The payload also had a strong relationship with initial thrust since this often determines engine size. Also, the initial thrust and the turning speed (the second angle parameter) seem to be the most sensitive parts of the trajectory. The staging altitude also had a large effect on the payload mass. The cost was most sensitive to initial thrust, since the cost was driven largely by engine mass. Staging altitude had a large impact, likely due to the way it affects the engine sizing for the second stage.

Some of the sensitivities are either both positive or both negative for payload mass and cost. This means that increasing the payload mass also increases the cost, so it does not make a strictly better design. For other design variables, the gradients show that the payload mass could be increased while reducing cost, so the point is not at a local maximum, unless it is at a bound. Heuristic algorithms do not ensure optimality. Some possible reasons the non-optimalities exist are that the sensitivities were low so minor variations were lost in the noise, or that discretization of the design variables did not allow the variables to be exact. This suggests that it could be useful to follow up with a gradient search. For the staging altitude variable the sensitivities are large and of opposite sign, but this is because that variable is up against its upper bound, and would like to increase but cannot.

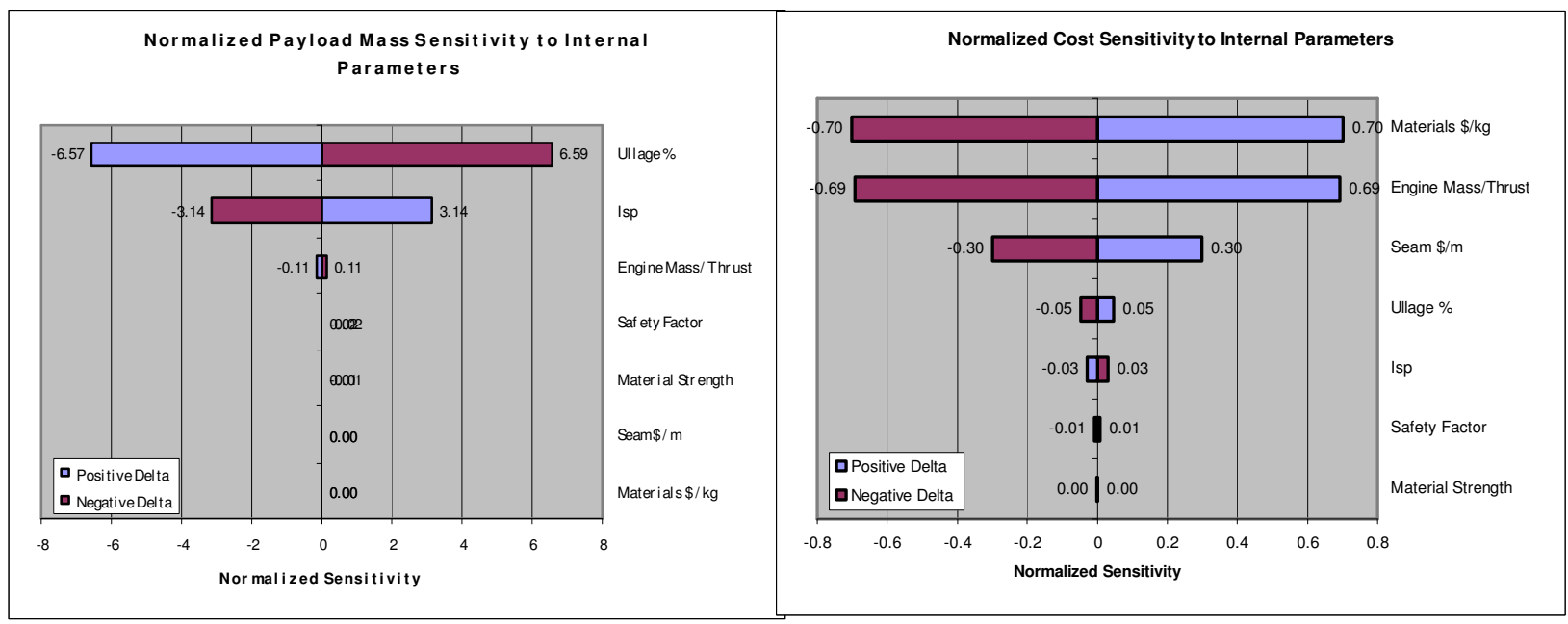

Figure 17. Normalized sensitivity of payload mass

Figure 18. Normalized sensitivity of cost to

to internal parameters

Figure 17 and Figure 18 show the normalized sensitivities, of the payload mass and cost respectively, to constants used in the model. The payload mass was most sensitive to the ullage percentage and the specific impulse. These directly affect the propellant used, which makes up the largest portion of the total rocket mass. The cost was most sensitive to the material and manufacturing costs, and also to the engine mass scaling, since the calculated engine cost scales directly with mass.

Several of these parameters have opposite signs for mass and cost sensitivity, but this does not represent a problem with the optimizer. What these sensitivities provide is an idea of the kinds of technology improvements that would provide the biggest impact to the rocket performance and cost. From Figure 17 and Figure 18 it seems that propulsive efficiency offers the most benefits, and costs for materials and manufacturing are of course important as well.

\section{Conclusion}

In this paper we developed a two-stage liquid rocket model with fifteen inputs, and payload mass and cost as outputs. The model was benchmarked and then optimized by a multi-objective genetic algorithm. After many runs, 
the MOGA was able to form a well-populated and fairly smooth Pareto front. There is no guarantee that these points are truly optimal, and a look at the sensitivity analysis suggests that they could be improved, at least slightly.

The optimal designs all preferred slender cones, high staging altitudes, and thrust angle profiles that began turning early over the first half of the flight. Some of the thrust profiles demonstrated a dip to lower maximum dynamic pressure. The rocket total wet mass, radius, and thrusts scaled with each other pretty evenly until the wet mass reached its upper bound, at which point the only increases were to the thrust, and to a lesser degree the radius. The smallest rockets used a denser fuel for their first stage, but most of the designs used the $\mathrm{LO}_{2}-\mathrm{LH}_{2}$ propellant with the maximum efficiency at all times.

Most of the subsystem models could be improved in fidelity. The cost model is currently based off of simple scalings, and would need to be much more complicated to be realistic, though the values are fairly close. Changing engine performance at different altitudes is not considered. Orbit circularization is handled with a simple burn at the end of the flight, and this may not be realistic.

Since the final designs from the MOGA could be improved slightly by simply adjusting the design variables slightly, it would be interesting to examine the benefits of using a gradient-based optimizer as a final step. This could improve the designs slightly by guiding the Pareto points to local maxima. Further sensitivity studies could be done to examine the effects of the bounds and constraints. Changing the constraints means the optimizer needs to be rerun, so this would be a more time-consuming evaluation. Another objective could be added to the model to measure risk or reliability, but these are very difficult to estimate or quantify.

The present model represents a two-stage liquid rocket model of intermediate fidelity and is available for design studies and optimizer benchmarking.

\section{Acknowledgments}

Brian Bairstow was supported through a NDSEG fellowship.

\section{References}

${ }^{1}$ Braun, R. D., Powell, R. W., Lepsch, R. A., Stanley, D. O., and Kroo, I. M., "Comparison of Two Multidisciplinary Optimization Strategies for Launch Vehicle Design," Journal of Spacecraft and Rockets, Vol. 32, No.3, May-June 1995, pp. 404410.

${ }^{2}$ Schoonover, P. L., Crossley, W. A., and Heister, S. D., “Application of a Genetic Algorithm to the Optimization of Hybrid Rockets," Journal of Spacecraft and Rockets, Vol. 37, No.5, September-October 2000, pp. 622-629.

${ }^{3}$ Tsuchiya, T., and Mori, T., "Optimal Conceptual Design of Two-Stage Reusable Rocket Vehicles Including Trajectory Optimization," Journal of Spacecraft and Rockets, Vol. 41, No.5, September-October 2004, pp. 770-778.

${ }^{4}$ Schuman, T., "Integration of System-Level Optimization With Concurrent Engineering Using Parametric Subsystem Modeling," Master's Thesis, Aeronautics and Astronautics Dept., Massachusetts Institute of Technology, Cambridge, MA, 2004.

${ }^{5}$ Taylor, C., "Single Stage to Orbit Rocket Model," Massachusetts Institute of Technology, Cambridge, MA, 2005.

${ }^{6}$ Sobieszczanski-Sobieski, J., "External Fuel Tank Model," AIAA Short Course on Multidisciplinary Design Optimization, NASA Langley Research Center, Hapton, VA, 2002.

${ }^{7}$ Kauffmann, J. W., Sippel, M., Schmid, V., "Mission Adapted Preliminary Design of Solid Rockets for Space Launch Systems," Joint Propulsion Conference and Exhibit, AIAA, Reston, VA, 1999.

${ }^{8}$ Tobias, M., Sauvageau, D. R., Hines, M., Geiser, N. L., "Five-Segment Booster Abort to Orbit Studies," Joint Propulsion Conference, AIAA, Reston, VA, 2002.

${ }^{9}$ U.S. Standard Atmosphere, 1962, U.S. Government Printing Office, Washington, D.C., 1962.

${ }^{10}$ Isakowitz, S. J., Hopkins, J. B., and Hopkins, J. P., Jr., International Reference Guide to Space Launch Systems, $4^{\text {th }}$ ed., AIAA, Virginia, 2004, pp. 109-146.

${ }^{11}$ Cohanim, B. E., Hewitt, J. N., de Weck, O., "The Design of Radio Telescope Array Configurations using Multiobjective Optimization: Imaging Performance versus Cable Length," The Astrophysical Journal Supplement Series, Vol. 154, October 2004, pp. 705-719.

${ }^{12}$ Ahuja, R. K., Orlin, J. B., Tiwari, A., “A Greedy Genetic Algorithm for the Quadratic Assignment Problem,” Computers and Operations Research, Vol. 27, 2000, pp. 917-934. 